\title{
Plasma levels of alarmin HNPs 1-3 associate with lung dysfunction after cardiac surgery in children
}

XiWang Liu', QiXing Chen', YuJia Luo ${ }^{1}$, YaoQin Hu${ }^{1}$, DengMing Lai', XiaoLe Zhang ${ }^{1}$, XiangHong Zhang ${ }^{1}$, JianGen $\mathrm{Yu}^{1}$, XiangMing Fang ${ }^{2^{*}}$ and Qiang Shu ${ }^{1 *}$

\begin{abstract}
Background: Early onset of lung injury is considerable common after cardiac surgery and is associated with increasing in morbidity and mortality, but current clinical predictors for the occurrence of this complication always have limited positive warning value. This study aimed to evaluate whether elevated plasma levels of human neutrophil peptides (HNPs) 1-3 herald impaired lung function in infants and young children after cardiac surgery necessitating cardiopulmonary bypass (CPB).

Methods: Consecutive children younger than 3 years old who underwent cardiac surgery were prospectively enrolled. Plasma concentrations of HNPs $1-3$ and inflammatory cytokines were measured before, and immediately after CPB, as well as at $1 \mathrm{~h}, 12 \mathrm{~h}$, and $24 \mathrm{~h}$ after CPB.

Results: Thirty patients were enrolled, $18(60 \%)$ of whom were infants. Plasma levels of HNPs $1-3$ and the pro-inflammatory cytokine interleukin-6 (IL-6) significantly increased immediately after CPB $(P<0.001)$, while $\mathrm{IL}-8$ increased $1 \mathrm{~h}$ after the $\mathrm{CPB}$ operation $(P=0.002)$. The anti-inflammatory cytokine IL-10 levels were also significantly elevated immediately after CPB compared with the baseline $(P<0.001)$. The stepwise multiple linear regression analysis showed that the plasma HNPs 1-3 levels immediately after CPB was independent correlated with the declined lung function, as reflected by the $\mathrm{PaO}_{2} / \mathrm{FiO}_{2}$ ratio on the first 2 days after operation (for the first day: $\mathrm{OR},-1.067,95 \% \mathrm{Cl},-0.548$ to -1.574 ; $\mathrm{P}<0.001$; for the second day: $\mathrm{OR},-0.667,95 \% \mathrm{Cl},-0.183$ to -1.148 ; $P=0.009)$ and prolonged mechanical ventilation time $(\mathrm{OR}, 0.039,95 \% \mathrm{Cl}, 0.005$ to $0.056 ; P=0.011)$. Plasma levels of HNPs 1-3 and IL-10 returned to the baseline values, while IL-6 and IL-8 levels remained significantly higher than baseline $24 \mathrm{~h}$ after CPB $(P \leq 0.01)$.

Conclusions: Elevated HNPs 1-3 levels immediately after CPB correlate with impaired lung function, and HNPs 1-3 could serve as a quantifiable early alarmin biomarker for onset of lung injury in infants and young children undergoing cardiac surgery with CPB.
\end{abstract}

Keywords: Human neutrophil peptides (HNPs) 1-3, Alarmin, Lung injury, Cardiac surgery, Cardiopulmonary bypass, Infant, Young children, Congenital heart disease

\footnotetext{
* Correspondence: xmfang@zju.edu.cn; shuqiang@zju.edu.cn

${ }^{2}$ Department of Anesthesiology, the First Affiliated Hospital, Zhejiang University School of Medicine, Hangzhou 310003, China

'Department of Thoracic \& Cardiovascular Surgery, Children's Hospital, Zhejiang University School of Medicine and Zhejiang Key Laboratory for Diagnosis and Therapy of Neonatal Diseases, 3333 Binsheng Road, Hangzhou 310003, China
} 


\section{Background}

Early onset of postoperative lung injury may occur in $12 \%$ to $50 \%$ of patients undergoing cardiac surgery necessitating cardiopulmonary bypass (CPB), with clinical manifestations ranging from mild postoperative dyspnoea to florid Acute Respiratory Distress Syndrome (ARDS) [1-3]. Up to $20 \%$ of the patients need ventilation for more than $48 \mathrm{~h}[3,4]$. The ARDS, appearance in $2 \%$ of these cases, carries a mortality of $40 \%$ to $80 \%[1,5]$. The etiology of post-CPB pulmonary dysfunction is multifactorial. Despite advances in perioperative management strategies [6], younger children are more prone to postoperative lung injury duo to the detrimental stimulation during cardiac surgery with CPB. Lung injury after surgery often leads to a prolonged length of hospital stay and subsequently increases in therapeutic costs and mortality [7-9]. Ideal therapy is limited by an incomplete understanding of the sentinel events involved in declined lung function, including both the relevant soluble mediators and cognate receptors that are operational when the process is most likely to be reversible $[1,10,11]$. The earlier the lung injury be detected, the much more successful treatment will be done $[3,8,12]$. Therefore, discovery and validation of certain alarmin biomarker for CPB-related lung injury in infants and young children undergoing cardiac surgery would be of great help for early diagnosis and efficient therapeutic decision making.

Human $\alpha$-defensins, a closely related family of six multifunctional cationic peptides, were the first endogenous mediators to be characterized as alarmins [13-15]. $\alpha-$ defensins 1-3, also called human neutrophil peptides (HNPs) 1-3, are sequestered within intracellular granules and released when polymorphonuclear leukocytes (PMNs) are activated $[15,16]$. Elevated levels of HNPs 1-3 have been found in the plasma and bronchoalveolar lavage fluid (BALF) of patients with inflammatory lung disease [17-20]. Furthermore, increased HNPs 1-3 levels are significantly correlated with the severity of lung function decline and clinical outcomes after acute lung injury [18, 20-23]. Recent studies have demonstrated that the release of HNPs $1-3$ by activated PMNs contributes to the initiation of acute lung injury by increasing both inflammatory response (activated inflammatory cells and immune recruitment, cytokine and chemokine production) and lung (microvascular and epithelial) permeability [24-26], as well as inducing apoptosis of the bronchial alveolar epithelial cells [26]. In addition, HNPs 1-3 could also suppress neutrophil apoptosis via the $\mathrm{P}_{2} \mathrm{Y}_{6}$ signaling pathway, which could leads to the amplification of the uncontrolled inflammation in lung [27], for neutrophils play a critical role as effector cells during acute lung injury.

These findings suggest that alarmin HNPs 1-3 may play a key role in the intricate of lung inflammatory response and contribute to the pathogenesis of lung injury.
Initial studies are promising. However, it is not clear whether these findings could extend to younger children undergoing cardiac surgery with CPB. This pilot study aimed to characterize the temporal kinetics of plasma alarmin HNPs 1-3 in infants and young children undergoing cardiac surgery with $\mathrm{CPB}$, and to investigate whether plasma HNPs 1-3 levels are associated with the impaired lung function after cardiac surgery.

\section{Methods \\ Study population}

This prospective study was conducted at a 1900-bed university children's hospital located in eastern China. The study protocols were approved by the hospital ethics committee (Medical Ethical Committee of the Children's Hospital of Zhejiang University), and informed consents were signed by supervisors of the patients. Children who were younger than 3 years and scheduled for cardiac surgery for congenital heart disease (CHD) were consecutively enrolled. The included patients had stable clinical conditions for at least 1 month. Patients were excluded if they were premature, had abnormal liver or renal function, had major chromosomal abnormalities, exhibited pulmonary inflammation before the surgery, had pulmonary edema due to cardiac dysfunction, required extracorporeal membrane oxygenation support after the operation, died because of cardiac dysfunction, or refused to participate in the study.

\section{Data collection and definitions}

During the surgical procedure, all patients underwent routine hemodynamic and blood gas surveillance. Anesthesia, the $\mathrm{CPB}$ procedure, ventilator settings and weaning from mechanical ventilation (MV) in the cardiac Intensive Care Unit (CICU) were all performed by using standard protocols, as shown in our previous studies and in additional material in detail [Additional file 1 and Additional file 2] $[9,28]$. The patients were transferred to the CICU immediately after operation and were given mechanical ventilated, still sedated and intubated.

Demographic and preoperative data were collected, including the patient's gender, age, weight, pulse oximetry saturation $\left(\mathrm{SpO}_{2}\right)$ at room air, $\mathrm{CPB}$ time, aortic cross-clamp (AC) time, operation time and duration of MV. The Risk Adjusted Classification for Congenital Heart Surgery (RACHS-1) for the operation was 2 to 4 degree. Arterial blood gas surveillance was done within $30 \mathrm{~min}$ after mechanical ventilated and then every $4 \mathrm{~h}$. The ratio of fraction of inspired oxygen to oxygen pressure $\left(\mathrm{PaO}_{2} / \mathrm{FiO}_{2}\right)$ was calculated. It would be checked if the $\mathrm{PaO}_{2} / \mathrm{FiO}_{2}$ was not dissatisfaction and also be done at any time according to the situation. The worst value of $\mathrm{PaO}_{2} / \mathrm{FiO}_{2}$ was record for analysis. Echocardiography was performed routinely to evaluate the cardiac function 
after surgery and at any time if necessary. The left ventricular function was evaluated according to the ejection fraction $(\mathrm{EF})$. A bedside chest radiograph was taken every day after surgery. Patients with cardiogenic pulmonary edema (CPE) were excluded. CPE was identified when the pulmonary arterial occlusion pressure was $>18 \mathrm{mmHg}$ or by the presence of at least two of the following: central venous pressure $>14 \mathrm{mmHg}$ left ventricular $\mathrm{EF}<45 \%$, systemic hypertension, or volume overload. Volume overload means cumulative fluid intake (including IV-administered medication, colloid, crystalloid and blood products) exceeding cumulative output (including urine, blood loss) during the observing period. Volume was given at the discretion of the attending cardiac intensivist or cardiovascular surgeon to maintain adequate circulatory parameters. In addition, all patients were followed up for CICU length of stay (LOS) and hospital LOS.

\section{Determination of HNP 1-3 and inflammatory cytokines in plasma}

For each patient, $2 \mathrm{ml}$ of fresh blood was drawn into a vacuum tube containing EDTA at the following time points: before $\mathrm{CPB}$, immediately after $\mathrm{CPB}$, as well as $1 \mathrm{~h}, 12 \mathrm{~h}$, and $24 \mathrm{~h}$ after $\mathrm{CPB}$ respectively. After being centrifuged at $3000 \mathrm{rpm}$ for $15 \mathrm{~min}$ at $4{ }^{\circ} \mathrm{C}$, the plasma was divided into aliquots and frozen at $-80{ }^{\circ} \mathrm{C}$ until assay.

HNP 1-3 levels were measured by using the commercially available ELISA kits (ALPHA DIAGNOSTIC INTERNATIONAL, USA), according to the manufacturer's instructions. The inflammation cytokines plasma levels were also determined with the ELISA kits ( $\& \& D$ Systems, USA), which include IL-6, IL-8, IL-10, IL-1 $\beta$ and TNF- $\alpha$. All the kits standards and samples run in duplicate. Laboratory staffs were blinded to clinical paraments of the patients, and investigators involved in collecting the demographic and preoperative data were blinded to cytokines levels.

\section{Statistical analysis}

Continuous data were tested for normal distribution with the one-sample Kolmogorov-Smirnov test. Variables were presented as mean values and standard deviations if normally distributed, and otherwise, as median values (interquartile range). Categorical data were presented as number (frequency). The Student $t$ test was used to determine the significance of variable differences between two time-points perioperatively. A Pearson or Spearman correlation test was performed to determine the correlation between plasma HNPs 1-3 data and clinical parameters $\left(\mathrm{PaO}_{2} / \mathrm{FiO}_{2}\right.$ ratio and $\mathrm{MV}$ time $)$. A stepwise multiple linear regression model was used to determine the independent risk factor for the clinical outcomes. The multivariate variables included age, weight, sex,
$\mathrm{CPB}$ time, operation time, $\mathrm{AC}$ time and the plasma concentrations of HNPs $1-3$, IL-6, IL-8 and IL-10. A $P$ value $<0.05$ was considered statistically significant. All statistical analyses were performed by using SPSS (SPSS 16.0 for Windows; SPSS, Chicago, IL, USA).

\section{Results \\ Study population}

Thirty consecutive patients younger than 3 years who underwent cardiac surgery were finally enrolled from January 1 to 31, 2017, which included 18 (60\%) infants. The general characteristics of the study patients are shown in Table 1. The cardiac defect of the patients included ventricular septal defect (VSD), VSD with atrial septal defect, VSD with patent ductus arteriosus, and tetralogy of Fallot. All patients underwent complete corrective surgery for cardiac lesion to ensure them no cyanosis after surgery. None of the cases need further surgical procedures for residual right to left shunt or other reasons. All of the children survived to hospital discharge.

\section{Perioperative HNPs 1-3 and inflammatory cytokines concentrations in plasma}

Plasma levels of HNPs 1-3 and the detected inflammatory cytokines are shown in Table 2. Plasma levels of HNPs $1-3$ increased immediately after CPB $(P<0.001)$. While twenty-four hours after $C P B$, the levels of HNPs 1-3 decreased and approached almost to the baseline levels (Table 2 and Fig. 1).

The plasma IL- 6 and IL-10 levels increased immediately after CPB $(P<0.001)$, while IL-8 increased $1 \mathrm{~h}$ after

Table 1 Demographic and clinical characteristics of the study population

\begin{tabular}{ll}
\hline Characteristic & \\
\hline Sex male n (\%) & $17(57 \%)$ \\
Age (months) & $12.8 \pm 8.9$ \\
Weight (kg) & $7.9 \pm 2.4$ \\
SpO2\% before operation (\%) & $95(88-99)$ \\
Pulmonary artery hypertension n (\%) & $11(37 \%)$ \\
CPB time (minutes) & $54.6 \pm 17.6$ \\
Operation time (minutes) & $106.4 \pm 25.4$ \\
AC time (minutes) & $33.6 \pm 15.2$ \\
Ultrafiltration volume (ml) & $33.7 \pm 15.8$ \\
Mechanical ventilation time (hours) & $12.6 \pm 7.9$ \\
CICU LOS (days) & $4.1 \pm 1.5$ \\
Hospital LOS (days) & $17.8 \pm 5.8$ \\
\hline $\begin{array}{l}\text { Data are presented as number of patients (\%), mean } \pm \text { SD, or median } \\
\text { (interquartile range), as appropriate }\end{array}$ SPO2 oxygen saturation, CPB cardiopulmonary bypass, AC aortic cross-clamp, \\
CICU cardiac Intensive Care Unit, LOS length of stay
\end{tabular}


Table 2 Perioperative plasma HNPs 1-3 and inflammatory cytokines levels

\begin{tabular}{llllll}
\hline Variables & Before CPB & After CPB & 1 h after CPB & 12 h after CPB & 24 h after CPB \\
\hline HNPs 1-3 (ng/ml) & $32.5 \pm 44$ & $224.9 \pm 100.4^{\mathrm{a}}$ & $220.4 \pm 91.3^{\mathrm{b}}$ & $85.6 \pm 58.3^{\mathrm{c}, \mathrm{d}}$ & $37.7 \pm 35.6^{\mathrm{e}}$ \\
$\mathrm{IL}-6(\mathrm{pg} / \mathrm{ml})$ & $3.5 \pm 6.3$ & $17 \pm 16.2^{\mathrm{a}}$ & $68.3 \pm 52.7^{\mathrm{b}, \mathrm{g}}$ & $139.7 \pm 101^{\mathrm{c}, \mathrm{d}}$ & $136.2 \pm 71.5^{\mathrm{e}, \mathrm{f}}$ \\
$\mathrm{IL}-8(\mathrm{pg} / \mathrm{ml})$ & $14.3 \pm 6.1$ & $37.8 \pm 26.3$ & $82.9 \pm 70.5^{\mathrm{h}, \mathrm{k}}$ & $29 \pm 17.5^{\mathrm{i}}$ & $26 \pm 14.6^{\mathrm{j}}$ \\
$\mathrm{IL}-10(\mathrm{pg} / \mathrm{ml})$ & $24.2 \pm 22.2$ & $400.7 \pm 236.5^{\mathrm{a}}$ & $1525.7 \pm 646.8^{\mathrm{b}, \mathrm{g}}$ & $66.4 \pm 43.3^{\mathrm{c}, \mathrm{d}}$ & $32.1 \pm 16.5^{\mathrm{e}}$ \\
\hline
\end{tabular}

Data are presented as mean \pm SD

${ }^{\mathrm{a}} P<0.001$ after $C P B$ versus before $C P B$;

${ }^{\mathrm{b}} \mathrm{P}<0.0011 \mathrm{~h}$ after $\mathrm{CPB}$ versus before $\mathrm{CPB}$;

${ }^{c} P<0.00112 \mathrm{~h}$ after $C P B$ versus before $C P B$;

${ }^{\mathrm{d}} P<0.00112 \mathrm{~h}$ after $C P B$ versus after $C P B$;

${ }^{\mathrm{e}} P<0.00124 \mathrm{~h}$ after $C P B$ versus after $C P B$;

${ }^{f} P<0.00124 \mathrm{~h}$ after CPB versus before CPB;

${ }^{9} P<0.0011 \mathrm{~h}$ after $C P B$ versus after $C P B$;

${ }^{\mathrm{h}} P=0.0021 \mathrm{~h}$ after $C P B$ versus before $C P B$;

${ }^{i} P=0.00712 \mathrm{~h}$ after $C P B$ versus before $C P B$;

${ }^{\mathrm{j}} P=0.0124 \mathrm{~h}$ after $C P B$ versus before $C P B$;

${ }^{\mathrm{k}} P<0.031 \mathrm{~h}$ after $C P B$ versus after $C P B$

CPB $(P=0.002)$. Twenty-four hours after CPB, the levels of IL-10 decreased near to the baseline levels, whereas IL- 6 and IL- 8 levels remained higher than the baseline levels $(P \leq 0.01)$. There were no significantly change in the plasma TNF- $\alpha$ and IL-1 $\beta$ levels during the selected perioperative times (data not show).

\section{Plasma HNPs 1-3 predict the severity and clinical outcome of lung injury}

Higher levels of plasma HNPs 1-3 at two time points (immediately after $\mathrm{CPB}$ and at $1 \mathrm{~h}$ after $\mathrm{CPB}$ ) were significantly associated with more severe lung injury, as reflected by the measurement of $\mathrm{PaO}_{2} / \mathrm{FiO}_{2}$ ratio on the first 2 days after operation (Fig. $2 \mathrm{a}-\mathrm{b}$ for the first day:
HNPs $1-3$ (immediately after CPB): $r=-0.641, P<0.001$; HNPs $1-3$ (1 h after CPB): $r=-0.379, P=0.039$; Fig. $2 \mathrm{c}-\mathrm{d}$ for the second day: HNPs 1-3(immediately after $\mathrm{CPB}$ ): $r=-0.471, P=0.009$; HNPs $1-3(1 \mathrm{~h}$ after $\mathrm{CPB}): \mathrm{r}=-0.4$, $P=0.029$ ). The plasma HNPs $1-3$ levels significantly increased immediately after $\mathrm{CPB}$, therefore the values at this time point were used for subsequent multivariable analysis. After adjusting for age, weight, sex, operation time, $\mathrm{CPB}$ time, AC time and the inflammatory cytokines (IL-6, IL-8 and IL-10) levels after CPB in a stepwise multiple linear regression model, we found that plasma HNPs 1-3 levels immediately after $\mathrm{CPB}$ was independently associated with the $\mathrm{PaO}_{2} / \mathrm{FiO}_{2}$ ratio on the first 2 days (for the first day: OR, -1.067 , 95\% CI, -0.548 to -1.574 ; $\mathrm{P}<0.001$; for

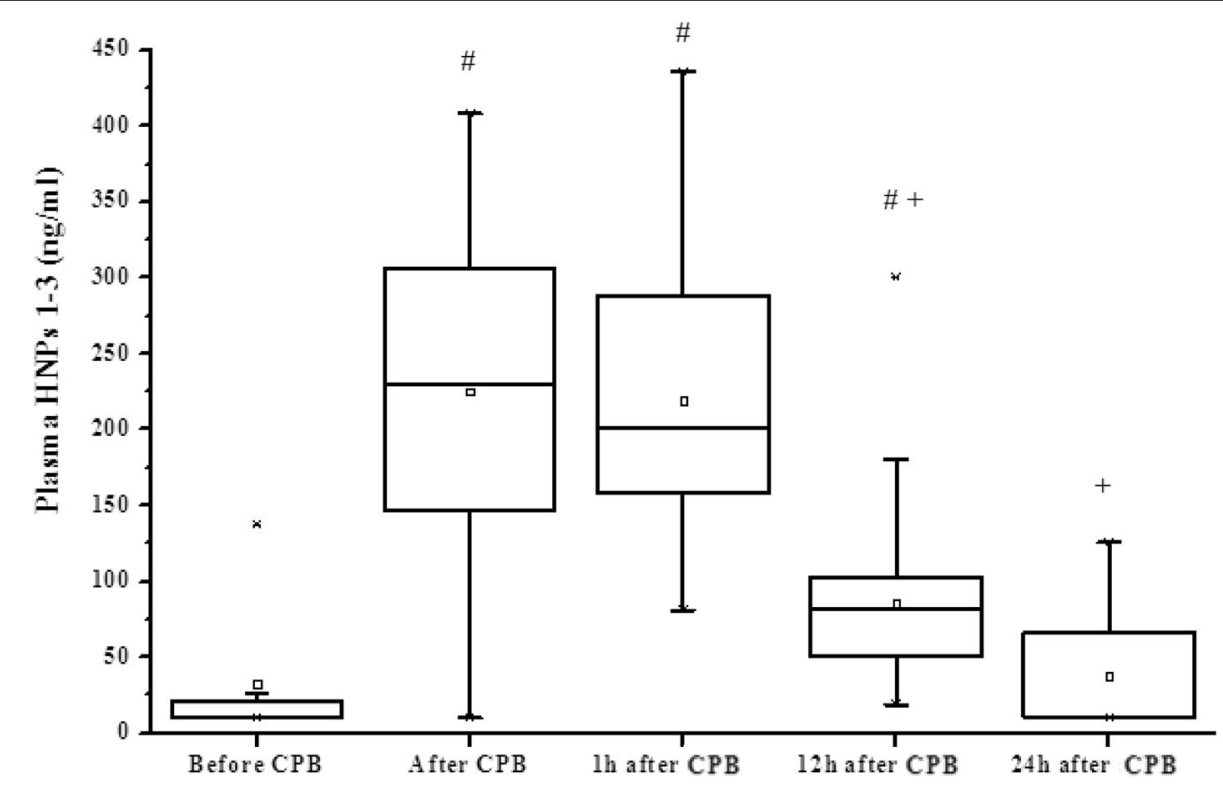

Fig. 1 Perioperative courses over time of plasma HNPs 1-3 levels in the group. Data are presented as mean, median, 25th and 75th percentile range and minimum and maximal values. \# Plasma HNPs 1-3 levels at different time points compares with that at the time before CPB; + Plasma HNPs 1-3 levels at different time points compares with that at the time after CPB. ${ }^{\#,+} P<0.001$. CPB, cardiopulmonary bypass 


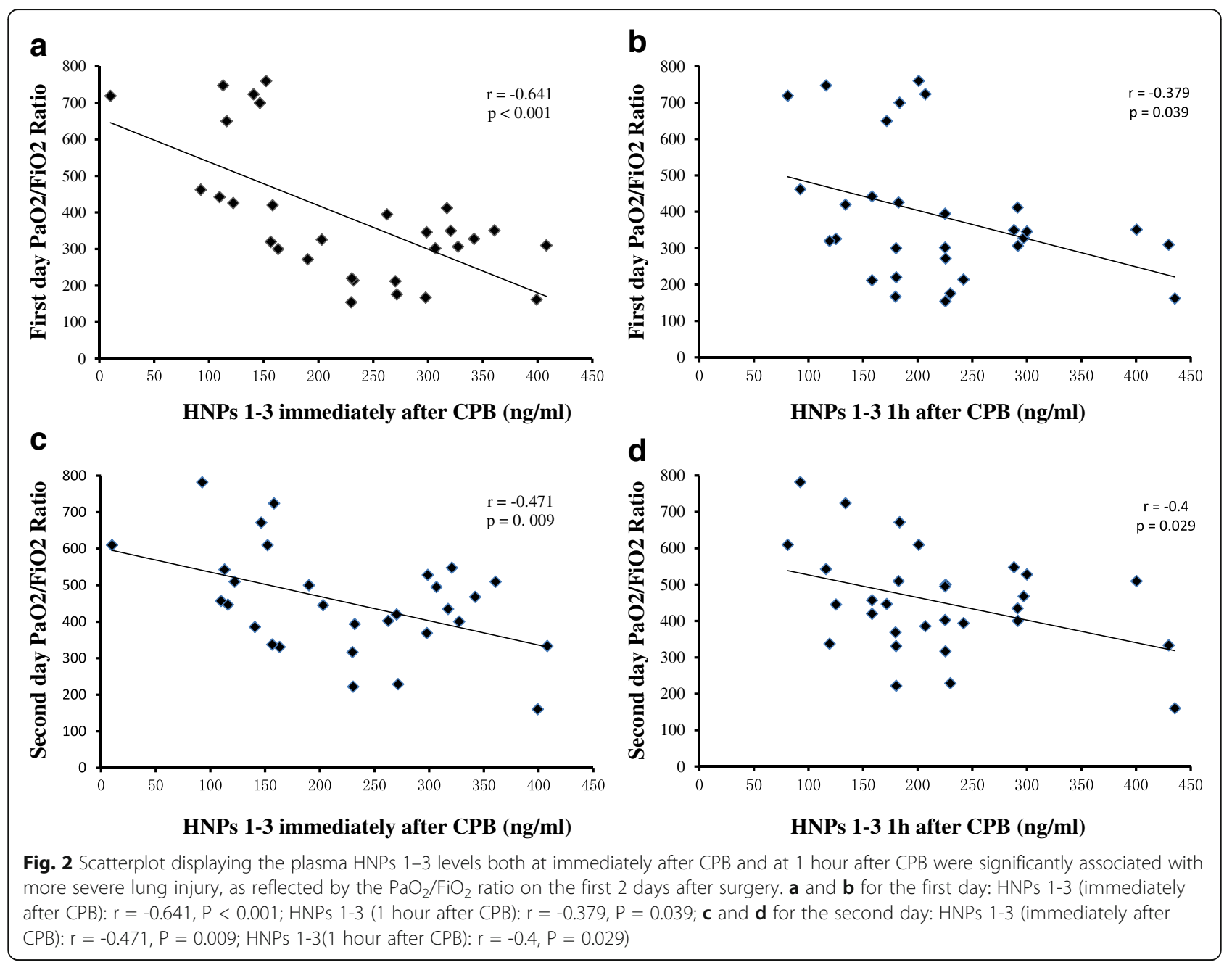

the second day: OR, $-0.667,95 \% \mathrm{CI},-0.183$ to -1.148 ; $P=0.009$ ). [Additional file 3: Table S1 and Additional file 4: Table S2].

Likewise, elevated plasma HNPs 1-3 levels immediately after $\mathrm{CPB}$ were correlated with longer MV time (Fig. 3, $r=0.46 ; P=0.011$ ). Even in the final multiple linear regression analysis, the HNPs $1-3$ levels were still independent risk factors for longer MV time (OR, 0.039; 95\% CI, 0.005 to $0.056 ; P=0.011$ ). [Additional file 5: Table S3].

\section{Discussion}

In this prospective pilot study of the perioperative kinetics of plasma HNPs 1-3 levels in infants and young children undergoing cardiac surgery with $\mathrm{CPB}$, we found that plasma concentrations of HNPs 1-3 remarkably increased immediately after $\mathrm{CPB}$. The elevated levels were correlated with the severity of lung function decline (as reflect by $\mathrm{PaO}_{2} / \mathrm{FiO}_{2}$ on the first day, $r=-0.641$ and second day, $r=-0.471$ after surgery) and clinical outcomes of lung injury after cardiac surgery with CPB. Alarmin HNPs 1-3 could serve as an early predictor for lung injury after cardiac surgery.

HNPs are 29-33 amino acid cationic peptides containing six cysteines that form three canonical intermolecular disulfide bonds which stabilize the surface $\beta$-sheet motifs. HNP-1 and -3 differ only in the $\mathrm{N}$-terminal amino acid, which, in HNP-1, is proteolyzed to generate HNP-2. There is no known functional difference among HNP-1 through -4 with respect to effects on host tissue [24, 29]. For HNP-1 through -3 comprise $97 \%$ of the total PMN pool, plasma HNPs $1-3$ were measured as alarmin of onset of lung injury after cardiac surgery in our study. Previous studies provided supportive evidence that HNPs $1-3$, increasing quickly in plasma and BALF $[20,22,30]$, initiate the early events in the pathogenesis of acute lung injury in inflammatory lung disease [19, 22, 24, 25]. High levels of HNPs 1-3 suggested more severe lung injury [18, 20-22, 24]. As expected, in the current study, we found that plasma levels of HNPs 1-3 were significantly elevated immediately after $\mathrm{CPB}$ and the HNPs 1-3 levels were related with the impaired lung 


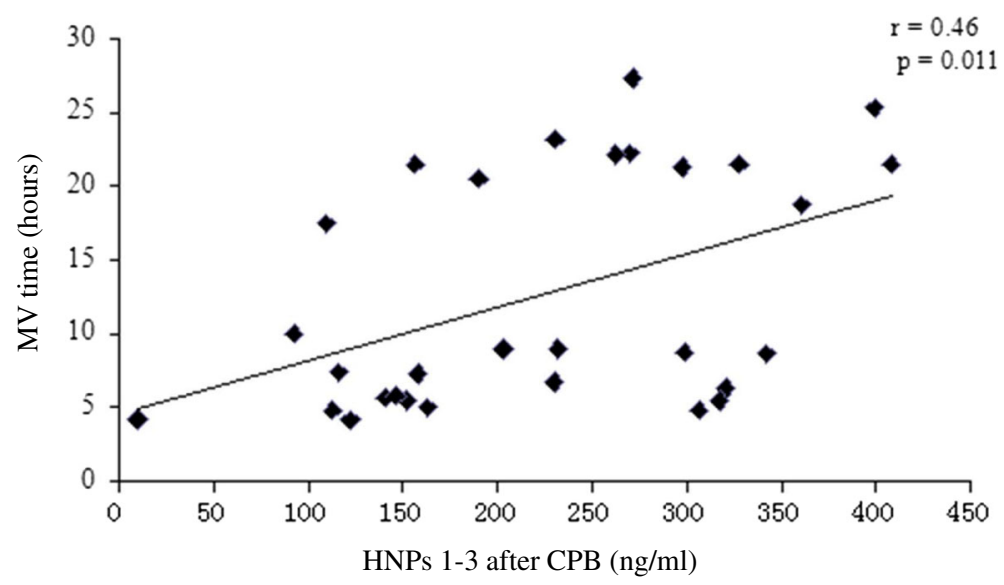

Fig. 3 Scatterplot displaying the plasma HNPs 1-3 levels immediately after CPB enable prediction day the mechanical ventilation time after the surgery. CPB, cardiopulmonary bypass; MV, mechanical ventilation

function, as reflected by the $\mathrm{PaO}_{2} / \mathrm{FiO}_{2}$ ratio on the first two days after cardiac surgery. After adjusting the clinical variants, which may impact this oxygenation index, HNPs 1-3 level remained as an independent risk factor for impaired oxygenation function after cardiac surgery. These findings suggested that plasma HNPs 1-3 levels could serve as a quantifiable alarmin for the post-CPB lung function decline in infants and young children. Unfortunately, to date, only a few studies have been conducted to HNPs $1-3$ as an alarmin of lung injury, which were always based on small number of patients $[20,24]$. Hence, a larger-cohort validation study is needed to verify these results in future. It should try to work out a cutoff value and/or predict positive value for lung dysfunction.

In addition, the present study found that plasma levels of HNPs 1-3 immediately after CPB were also positively correlated with the duration of MV $(r=0.46)$. Although speculative, the following reasons might explain these correlations. Recently, Liu et al. [26] reported that neutrophil-derived $\alpha$-defensin had directly concentrationdependent pro-inflammatory and apoptotic effects in human bronchial and alveolar epithelial cells. It was verified by the latter fact that, in the transgenic mice, which express human a-defensin, neutrophil HNPs 1-3 contributes to the initiation of acute lung injury through low-density lipoprotein-related receptor-mediated disrupting capillaryepithelial barrier function within $4 \mathrm{~h}$ after acid aspiration [24]. The effects of HNPs $1-3$ are not attenuated by plasma or tissue proteins that inhibit cytotoxicity, likely because of the high local concentrations attained when the protein is rapidly released from PMNs adherent to endothelial and epithelial cells [24, 29]. The facts indicate that HNPs 1-3 participate in the early events of lung injury directly. Intriguingly, in ARDS patients, the first twelve-hour plasma HNPs levels were found to closely correlate with the release of CRP, IL-8 and G-CSF in the circulation and with the severity of lung injury [20]. Otherwise, in vitro, stimulation of primary small airway epithelial cells with HNPs 1-3 induced expression of pro-inflammatory cytokines (IL-6, IL-8, IL-1 $\beta$, IL-13, MCP-1 and 100A proteins), adhesion molecules (ICAM and VCAM), MMP-9 and $\beta$-defensins-2, but significantly decreased the expression of anti-inflammatory cytokine IL-10 [17, 22, 24, 26, 30, 31]. These cytokines were always reported to aggravate the HNPs 1-3 induced lung cell damage, lung (microvascular and epithelial) permeability and further diapedesis $[1,2,4,24,28]$. The infiltration of effector is mediated, at least in part, by the chemotactic activity of HNPs $1-3$, the first characterized alarmin. The infiltrated cytotoxicity cells, attracted by HNPs 1-3, often perform synergistically effects with the multifunctional peptides on process pathophysiology of acute lung injury $[22,24,25,27]$. On the other hand, importantly, HNPs 1-3 were reported to suppress neutrophil apoptosis via the $\mathrm{P}_{2} \mathrm{Y}_{6}$ signaling pathway resulting in the prolongation of their lifespan [27]. The prolonged survival of activated neutrophils in patients with ARDS, can cause the uncontrolled release of cytotoxic metabolites and proinflammatory substances (i.e., reactive oxygen species and proteases), which leads to the amplification of systemic inflammation, tissue injury and organ failure [27, 32]. Taken together, HNPs 1-3 contribute to more severe and prolonged inflammation in the lung and damage of the alveolar capillary barrier with increased lung water content and impaired oxygenation, inevitably resulting in longer MV support. There was no doubt that the HNPs 1-3 played an important role in the development of lung injury after cardiac surgery with $\mathrm{CPB}$. It is necessary to prove that HNPs 1-3 are mediators of lung injury in patients after cardiac surgery and not merely makers of disease in future. 
Notably, HNPs 1-3 gene polymorphisms have been found to affect the expression level and associate with lung function in pathologic states [21, 29, 33, 34], it should be emphasized that genetic variation of HNPs 1-3 must be considered in future. Further studies aimed at elucidating the aforementioned issues would help gain additional insight into the mechanism by which these alarmins modulate lung injury after cardiac surgery.

Previous studies have shown that normal plasma contained miniscule amounts of HNPs 1-3, usually below $100 \mathrm{ng} / \mathrm{ml}$, and although the concentration of HNPs 1-3 was considerably higher in plasma of patients with sepsis or inflammatory lung disease, most of these peptides would be protein bound [24, 29, 35]. In the current pilot study, we found similar kinetics of plasma HNPs 1-3 perioperatively in children that the elevated plasma HNPs 1-3 levels descend twenty-four hours after operation. The notoriously 'non-specific' binding proclivities may, to some extent, account for the short lifetime of HNPs 1-3 in plasma. No degradative pathway for their removal from tissue has been identified. Another possible explanation for this decrement is the ingestion of HNPs 1-3 by peripheral blood mononuclear cells, for previous studies have shown that these cells can capture defensins in various ways after a much mount of HNPs suddenly released into the circulation [29, 36]. In addition, the expression of $\alpha$-defensins significantly correlated with the proportion and number of airway neutrophils [19]. Although patient with relative higher levels HNPs 1-3 concentration in patients had longer MV time in the study, factors activating neutrophil gradually disappeared with the patients weaning from the ventilator, which down regulated the release HNPs 1-3 from neutrophil [3, 9]. Interestingly, plasma HNPs 1-3 concentrations returned to the normal range after pulmonary inflammatory disease was treatment, which followed with reduction of the activated neutrophil count [37].

Several issues of the present study should be noticed with caution. First, we used the current AmericanEuropean Consensus Conference (AECC) definitions for acute lung injury and ARDS to definite the impaired lung function regardless of $\mathrm{FIO}_{2}$ or PEEP. Although the predict value of the alarmin HNPs 1-3 for the occurrence of acute lung injury in this study is consistent with that in previous published studies [17, 18, 20, 22], our relative weak correlation findings were based on a small number of patients in a single center, which might limit the application of these findings to other institutions. Furthermore, we enrolled the patients underwent surgery for CHD in the absence of relevant comorbidities and particularly of known lung disease. Therefore, we are not sure whether the HNPs $1-3$ changes would be the same in the presence of previous lung diseases.
Because children often have pneumonias before cardiac operations, future studies are needed to confirm this. Third, the HNPs 1-3 levels in BALF were not measured in this study. However, the intriguing findings indicated that elevated of HNPs 1-3 in plasma significantly correlated with the proportion and number of airway neutrophils $[17,19,37]$. In addition, the accumulation of airway neutrophils is reported to be directly associated with the activation state of circulating neutrophils $[19,20]$, which, to some extent, suggests that HNPs $1-3$ in pulmonary may have the similar kinetics and functions in lung injury.

\section{Conclusions}

We found that plasma HNPs $1-3$ could act as a quantifiable alarmin biomarker for onset of lung injury after cardiac surgery with $\mathrm{CPB}$ in infants and young children. The plasma levels of HNPs 1-3 are associated with lung function and clinical outcomes after $\mathrm{CPB}$. Insight into the role of the HNPs $1-3$ in the post-cardiac surgery inflammatory response holds the potential for better understanding of pulmonary dysfunction induced by cardiac surgery necessitating $\mathrm{CPB}$.

\section{Additional files}

Additional file 1: Standard anesthesia and cardiopulmonary bypass protocol. (DOCX 14 kb)

Additional file 2: Ventilator settings and Wean from mechanical ventilation protocol. (DOCX $14 \mathrm{~kb}$ )

Additional file 3: Table S1. Multiple linear regression model analysis independent risk factors associated with $\mathrm{PaO} 2 / \mathrm{FiO} 2$ ratio on the first day after CPB operation. (DOCX $15 \mathrm{~kb}$ )

Additional file 4: Table S2. Multiple linear regression model analysis independent risk factors associated with $\mathrm{PaO} 2 / \mathrm{FiO} 2$ ratio on the second day after CPB operation. (DOCX $15 \mathrm{~kb}$ )

Additional file 5: Table S3. Multiple linear regression model analysis independent risk factors associated with prolonged MV time after CPB operation. (DOCX $15 \mathrm{~kb}$ )

\section{Abbreviations}

AC: Aortic cross-clamp; ARDS: Adult respiratory distress syndrome; BALF: Bronchoalveolar lavage fluid; CHD: Congenital heart disease; CICU: Cardiac Intensive Care Unit; CPB: Cardiopulmonary bypass; CPE: Cardiogenic pulmonary edema; EF: Ejection fraction; HNPs 1-3: Human neutrophil peptides (HNPS) 1-3; LOS: Length of stay; MV: Mechanical ventilation; PMNs: Polymorphonuclear leukocytes; RACHS-1: The Risk Adjusted Classification for Congenital Heart Surgery; $\mathrm{SpO}_{2}$ : Pulse oximetry saturation

\section{Acknowledgements}

We thank all the patients and the supervisors who agreed to participate in this study.

\section{Funding}

This work was partly financially supported by the National Natural Science Foundation of China (No. 81671956, 81,301,612, 81,571,872 and 81,130,036) and The Zhejiang Provincial Program for the Cultivation of High-level Innovative Health Talents (2016-6). No. 81671956 and 81,301,612 supported to the design and the data analysis of the study, NO. 81571872 supported in data collecting, NO. 81130036 supported to detect the cytokine levels in the plasma. The Zhejiang Provincial Program for the Cultivation of High-level Innovative 
Health Talents (2016-6) supported in improving the English language usage in writing the manuscript.

\section{Availability of data and materials}

The datasets used and analyzed during the current study are available from the corresponding author on reasonable request.

\section{Authors' contributions}

XWL: was instrumental in developing the study hypothesis and was intimately involved in interpretation of the results as well as manuscript preparing. He was also involved in data extraction as well as statistics. He has full access to the data, read the final version of the manuscript and agrees with all reported findings and interpretations. QXC: was instrumental in the performance of coordination of the study, data gathering and analysis. He has revised the manuscript critically for important intellectual content, read the final version of the manuscript and agrees with all reported findings and interpretations. DML and $Y J L$ were instrumental in the performance of laboratory analysis. They were also intimately involved with interpretations of the results and manuscript. XLZ and $\mathrm{YQH}$ were instrumental in the performance of data gathering. They were also intimately involved with interpretations of the results and manuscript. $\mathrm{XHZ}$ and JGY were instrumental in enroll the patients and signed the consents with the supervisors of the patients. They were revised the manuscript critically for important intellectual content, read the final version of the manuscript and agrees with all reported findings and interpretations. XMF and QS: were instrumental in study hypothesis and design. They were revised the manuscript critically for important intellectual content, read the final version of the manuscript and agrees with all reported findings and interpretations. All authors read and approved the final manuscript.

\section{Ethics approval and consent to participate}

The study protocols were approved by the Medical Ethical Committee of the Children's Hospital of Zhejiang University. Informed consents were signed by supervisors of the patients, who agreed to participate in the current study.

\section{Consent for publication}

Not applicable.

\section{Competing interests}

The authors declare that they have no competing interests.

\section{Publisher's Note}

Springer Nature remains neutral with regard to jurisdictional claims in published maps and institutional affiliations.

Received: 23 March 2017 Accepted: 7 December 2017 Published online: 28 December 2017

\section{References}

1. Stephens RS, Shah AS, Whitman GJ. Lung injury and acute respiratory distress syndrome after cardiac surgery. Ann Thorac Surg. 2013;95(3):1122-9.

2. Tuinman PR, Cornet AD, Kuipers MT, Vlaar AP, Schultz MJ, Beishuizen A, et al. Soluble receptor for advanced glycation end products as an indicator of pulmonary vascular injury after cardiac surgery. BMC Pulm Med. 2013;13:76.

3. Ohata K, Chen-Yoshikawa TF, Menju T, Miyamoto E, Tanaka S, Takahashi M, et al. Protective effect of inhaled rho-kinase inhibitor on lung ischemiareperfusion injury. Ann Thorac Surg. 2017;103(2):476-83.

4. Clark SC. Lung injury after cardiopulmonary bypass. Perfusion. 2006;21(4):225-8

5. Rong LQ, Di Franco A, Gaudino M. Acute respiratory distress syndrome after cardiac surgery. J Thorac Dis. 2016;8(10):E1177-86.

6. Yang ZH, Ning BT, Zhang CM, Lin R, Ye S, Liu T. Clinical application of extracorporeal membrane oxygenation in children with refractory cardiopulmonary failure. World J Pediatr. 2016;12(3):364-7.

7. López-Fernández Y, Azagra AM, de la Oliva P, Modesto V, Sánchez II, Parrilla J, et al. Pediatric acute lung injury epidemiology and natural history study: incidence and outcome of the acute respiratory distress syndrome in children. Crit Care Med. 2012;40(12):3238-45.

8. Mazine A, Rached-D'Astous S, Ducruet T, Lacroix J, Poirier N. Pediatric Acute Lung Injury and Sepsis Investigators Network. Blood transfusions after pediatric cardiac operations: a north American multicenter prospective study. Ann Thorac Surg. 2015;100(2):671-7.
9. Shi S, Zhao Z, Liu X, Shu Q, Tan L, Lin R, et al. Perioperative risk factors for prolonged mechanical ventilation following cardiac surgery in neonates and young infants. Chest. 2008;134(4):768-74.

10. Markou T, Chambers DJ. Lung injury after simulated cardiopulmonary bypass in an isolated perfused rat lung preparation: role of mitogenactivated protein kinase/Akt signaling and the effects of theophylline. J Thorac Cardiovasc Surg. 2014;148(5):2335-44.

11. Mazzeffi M, Rock P. Should we prone cardiac surgery patients with acute respiratory distress syndrome? Ann Thorac Surg. 2014;97(3):1122.

12. Turnbull AE, Ruhl AP, Lau BM, Mendez-Tellez PA, Shanholtz CB, Needham DM. Timing of limitations in life support in acute lung injury patients: a multisite study. Crit Care Med. 2014;42(2):296-302.

13. Qi YY, Zhou XJ, Cheng FJ, Zhang H. Elevated plasma a-Defensins (HNP1-3) levels correlated with IgA1 glycosylation and susceptibility to IgA nephropathy. Dis Markers. 2016;2016:8123138.

14. Dong H, Lv Y, Zhao D, Barrow P, Zhou X. Defensins: the case for their use against mycobacterial infections. J Immunol Res. 2016;2016:7515687.

15. Chen Q, Jin Y, Zhang K, Li H, Chen W, Meng G, et al. Alarmin HNP-1 promotes pyroptosis and IL-1 $\beta$ release through different roles of NLRP3 inflammasome via P2X7 in LPS-primed macrophages. Innate Immun. 2014;20(3):290-300

16. Selsted ME, Ouellette AJ. Mammalian defensins in the antimicrobial immune response. Nat Immunol. 2005;6(6):551-7.

17. Baines KJ, Upham JW, Yerkovich ST, Chang AB, Marchant JM, Carroll M, et al. Mediators of neutrophil function in children with protracted bacterial bronchitis. Chest. 2014;146(4):1013-20.

18. Paone G, Conti V, Vestri A, Leone A, Puglisi G, Benassi F, et al. Analysis of sputum markers in the evaluation of lung inflammation and functional impairment in symptomatic smokers and COPD patients. Dis Markers. 2011;31(2):91-100.

19. Baines KJ, Simpson JL, Wood LG, Scott RJ, Gibson PG. Systemic upregulation of neutrophil a-defensins and serine proteases in neutrophilic asthma. Thorax. 2011:66(11):942-7.

20. Ashitani J, Mukae H, Arimura Y, Sano A, Tokojima M, Nakazato M. High concentrations of alpha-defensins in plasma and bronchoalveolar lavage fluid of patients with acute respiratory distress syndrome. Life Sci. 2004;75(9):1123-34.

21. Wallace AM, He JQ, Burkett KM, Ruan J, Connett JE, Anthonisen NR, et al. Contribution of alpha- and beta-defensins to lung function decline and infection in smokers: an association study. Respir Res. 2006;7:76.

22. Tiriveedhi V, Banan B, Deepti S, Nataraju A, Hachem R, Trulock E, et al. Role of defensins in the pathogenesis of chronic lung allograft rejection. Hum Immunol. 2014;75(4):370-7.

23. Han W, Wang W, Mohammed KA, Alpha-defensins SY. Increase lung fibroblast proliferation and collagen synthesis via the beta-catenin signaling pathway. FEBS J. 2009;276(22):6603-14.

24. Bdeir K, Higazi AA, Kulikovskaya I, Christofidou-Solomidou M, Vinogradov SA, Allen TC, et al. Neutrophil alpha-defensins cause lung injury by disrupting the capillary-epithelial barrier. Am J Respir Crit Care Med. 2010;181(9):935-46.

25. Saini D, Angaswamy N, Tiriveedhi V, Fukami N, Ramachandran S, Hachem R, et al. Synergistic effect of antibodies to human leukocyte antigens and defensins in pathogenesis of bronchiolitis obliterans syndrome after human lung transplantation. J Heart Lung Transplant. 2010;29(12):1330-6.

26. Liu CY, Lin HC, Yu CT, Lin SM, Lee KY, Chen HC, et al. The concentrationdependent chemokine release and pro-apoptotic effects of neutrophilderived alpha-defensin-1 on human bronchial and alveolar epithelial cells. Life Sci. 2007:80(8):749-58.

27. Nagaoka I, Suzuki K, Murakami T, Niyonsaba F, Tamura H, Hirata M. Evaluation of the effect of a-defensin human neutrophil peptides on neutrophil apoptosis. Int J Mol Med. 2010;26(6):925-34.

28. Liu X, Chen Q, Shi S, Shi Z, Lin R, Tan L, et al. Plasma sRAGE enables prediction of acute lung injury after cardiac surgery in children. Crit Care. 2012;16(3):R91.

29. Lehrer Rl, Lu W. a-Defensins in human innate immunity. Immunol Rev. 2012;245(1):84-112.

30. Vento G, Lio A, Tirone C, Aurilia C, Tana M, Piras A, et al. Association of high levels of a-defensins and S100A proteins with Candida mannan detection in bronchoalveolar lavage fluid of preterm neonates. Pediatr Res. 2013;74(1):19-25.

31. Amenomori M, Mukae H, Ishimatsu Y, Sakamoto N, Kakugawa T, Hara A, et al. Differential effects of human neutrophil peptide-1 on growth factor and interleukin-8 production by human lung fibroblasts and epithelial cells. Exp Lung Res. 2010;36(7):411-9. 
32. Lv J, Xiong Y, Li W, Yang W, Zhao L, He R. BLT1 Mediates Bleomycin-Induced Lung Fibrosis Independently of Neutrophils and CD4+ T Cells. J Immunol 2017; 198(4):1673-1684.

33. Xu R, Feng $S$, Li Z, Fu Y, Yin P, Ai Z, et al. Polymorphism of DEFA in Chinese Han population with IgA nephropathy. Hum Genet. 2014;133(10):1299-309.

34. Chen $Q$, Hakimi M, Wu S, Jin Y, Cheng B, Wang H, et al. Increased genomic copy number of DEFA1/DEFA3 is associated with susceptibility to severe sepsis in Chinese Han population. Anesthesiology. 2010;112(6):1428-34.

35. Lehrer RI, Jung G, Ruchala P, Andre S, Gabius HJ, Multivalent LW. Binding of carbohydrates by the human alpha-defensin, HD5. J Immunol. 2009;183(1):480-90.

36. Arnett E, Lehrer RI, Pratikhya P, Lu W, Seveau S. Defensins enable macrophages to inhibit the intracellular proliferation of listeria monocytogenes. Cell Microbiol. 2011;13(4):635-51.

37. Ashitani J, Mukae H, Hiratsuka T, Nakazato M, Kumamoto K, Matsukura S.

Elevated levels of alpha-defensins in plasma and BAL fluid of patients with active pulmonary tuberculosis. Chest. 2002;121(2):519-26.

Submit your next manuscript to BioMed Central and we will help you at every step:

- We accept pre-submission inquiries

- Our selector tool helps you to find the most relevant journal

- We provide round the clock customer support

- Convenient online submission

- Thorough peer review

- Inclusion in PubMed and all major indexing services

- Maximum visibility for your research

Submit your manuscript at www.biomedcentral.com/submit
Biomed Central 